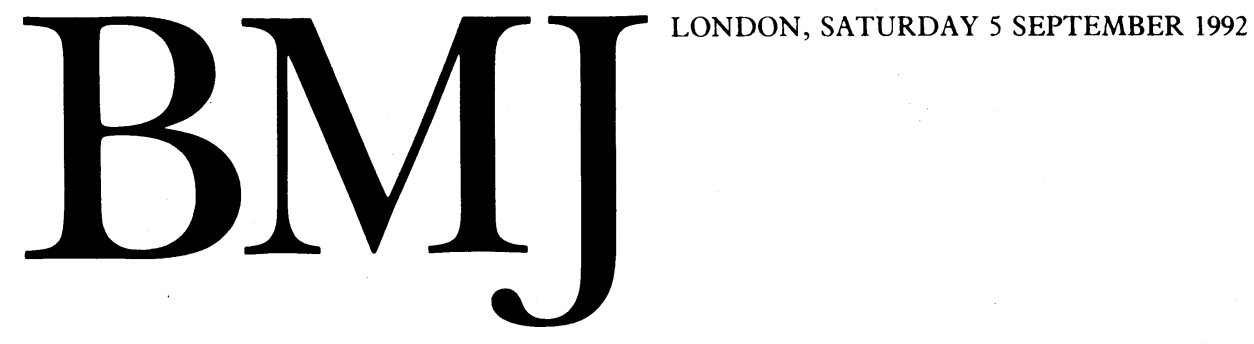

\title{
Local voices
}

\section{The bankruptcy of the democratic process}

To pursue its aim of making health authorities "champions of the people," the NHS Management Executive earlier this year issued guidance for purchasing authorities on gathering and using the views of local people. ${ }^{1}$ Because of its emphasis on market research Local Voices ${ }^{1}$ can be seen as the latest chapter in the history of consumerism in the health service. But it can also be seen as marking the demise of local democratic accountability in the NHS. It and other publications on ways of involving the consumer ${ }^{2-5}$ concentrate almost entirely on the processes of consultation. There is no comment on the tensions inherent in consulting within the internal market. In particular, there has been no attempt to examine whether the intended result of health authorities' role as champions of the people- "decisions should reflect what people want, their preferences, concerns, and values"is feasible.

Local Voices sets out a district communications strategy based on the "imperatives" of listening, informing, discussing, and reporting. It also includes a list of well established market research techniques, ranging from patient satisfaction questionnaires to interviews, complaints procedures, and public meetings, with 19 examples of good practice. ${ }^{\prime}$ There are, however, many difficulties with the listen, discuss, inform, and report approach.

First is the issue of representation. Purchasers struggle to understand whose views are being listened to. Since community participants are usually identified by community health councils it is sometimes unclear whether they are representing individuals, groups within the community, or the voluntary sector, and this becomes especially important when changes in service provision or priorities are proposed.

Secondly, discussions among purchasers, providers, and community participants often show a mismatch between professional and lay perceptions of need. For example, consumer representatives often complain about the dominance of the medical model in mental health and other services. Such conflicts are not easily resolved when resources are insufficient to cope with current workloads, let alone to develop new innovative services. Moreover, discussions which expose "unmet need" may result in community participants being asked to identify what elements of current service provision should be forgone. Again this raises the question of the legitimacy of local decision making in the absence of democratic structures for local accountability.

Thirdly, despite anguished debates about priorities and rationing there is no discussion on why the government is abdicating responsibility for resource allocation by devolving decisions to local managers and individual members of the public. Formerly health care judgments were depoliticised through clinical decision making, where at least there was some technical expertise to inform a complex debate.

Fourthly, attempts by purchasers to inform discussions and debates are hindered by the absence of information on outcomes, costs, and effectiveness. Many purchasers and providers are still unfamiliar with the type and range of information required to evaluate quality and outcome of services. Complex technical issues are not always easily shared even with people working within the service.

Finally, how do purchasers report back to community participants when they are faced with having to admit that there are insufficient data and resources to develop suggested innovations in services, and how do purchasers explain the complex symbiotic relations between purchasers and providers without committing political suicide?

Consumerism in the NHS is not new, and was partly responsible for giving rise to community health councils in 1974. ${ }^{7}$ However, criticism of community health councils' lack of representativeness and power, and the ambiguity of their role as observers at health authority meetings, ${ }^{89}$ resulted in the green paper Patients First proposing their abolition in 1979. ${ }^{10}$ But in the days when a government would publish the responses to consultation, and the secretary of state could write in its foreword, "It is important for the public... to judge how far these decisions have been supported or opposed," the consultation disclosed much public support for community health councils. ${ }^{11}$

Local Voices now implies that the long stay of execution may be over. As health authorities seek direct access to groups and individuals in the community the role of the community health council diminishes. But by reducing public participation to individual consultation reasoned responses and protests by the public to changes in the NHS are also made harder.

Local Voices does not mention the consultation process which existed up until 1991. Although local democracy was considerably weakened in the second NHS reorganisation in 1982, district health authorities still included local authority representatives. The white paper's justification for reconstituting health authorities with all five non-executive members nominated by the regional health authority was that "the [former] DHA was neither truly representative (of the local community) nor a management body." Hence "authorities 
based upon this confusion of roles would not be equipped to handle the complex managerial and contractual issues that the new system of matching resources to performance will demand." new management role of DHAs to include being champions of the people will restore this confusion of roles.

Members report that health authority meetings since the 1991 changes have been more comfortable and friendly and that decision making is easier, ${ }^{13}$ especially since they are increasingly held in private. ${ }^{1+}$ But there has been little debate on the impact of membership on the new reforms or on the effect of large purchasing consortia and district mergers, which remove health authority members still further from their communities. ${ }^{\text {t4 }}$

The model of direct ministerial management of health care, with its focus on individual consultation, is a long way from the 1944 green paper, which originally intended that local authorities should run health services and special professional and technical guidance would be provided by local health services councils. ${ }^{15}$ Then, in rejecting the suggestion that experts should be included in local authority administration of health services, the government felt, "The risk of impairing the principle of public responsibility (accountability) - that effective decisions on policy must lie entirely with elected representatives answerable to the people for the decisions that they take-outweighs any advantages likely to accrue."

Recent research shows that local democracy does count. ${ }^{16}{ }^{17}$ Regardless of their political opinions, people identify with and value the role of their local authorities in decision making. Many of the debates throughout the 1980s indicate that there is no reason to believe that they would not support a more democratic health service. ${ }^{18} 19$

If the NHS Management Executive is having second thoughts about whether the new district health authorities and their members can fulfil their management role and be champions of the people then it has to realise that market research models can never be a substitute for a democratic process and local accountability. Otherwise community consultation, consumerism, and participation in needs assessment, priority setting, and developing and monitoring service specifications are meaningless.

ALLYSON M POLLOCK

Senior Registrar in Public Health Medicine,

Bloomsbury and Islington Health Authority,

London NW1 2LJ

1 NHS Management Executive. Local voices. The views of local people in purchasing for health. London: NHSME, 1992

National Consumer Council. Involving the community. Guidelines for health service managers. London: NCC, 1992.

3 Winn L, ed. Power to the people. The key to responsive services in health and social care. London: King's Fund Centre, 1990.

4 McIvor S. Obtaining the views of health service users. London: King's Fund Centre, 1991.

5 Levenson R, Joule N. Listening to people. User involvement in the NHS - the challenge for the future. London: Greater London Association of Community Health Councils, 1992.

7 Farrel C, Levitt R. Consumers, community health councils and the NHS. London: King's Fund Centre, 1980.

8 Royal Commission on the NHS. Report. London: HMSO, 1979.

9 Hogg C. The public and the NHS. Birmingham: Association of Community Health Councils in England and Wales, 1986

10 Department of Health and Social Security. Patients first: consultative paper on the structure and management of the NHS in England and Wales. London: HMSO, 1979.

11 Department of Health and Social Security. Patients first: summary of the comments received on the consultation paper. London: DHSS, 1980.

2 Department of Health. Working for patients. London: HMSO, 1989.

13 Ashburner L, Cairncross A. Authorities in the NHS. Members: attitudes and expectations. Warwick: University of Warwick Centre for Corporate Strategy, 1992. (Research for Action. Paper 5.)

14 Ham C, Matthews T. Purchasing with authority: the new role of DHAs. London: King's Fund College, 1991 .

15 Ministry of Health, Department of Health for Scotland. A National Health Service. London:

HMSO, 1944.
16 Broom D. Does local democracy count? Search 1991; Nov 11:5-7.

17 Attitudes to local government. A survey of electors. York: Joseph Rowntree Foundation, 1991.

18 Community-consumer representation in the NHS, with specific reference to community health councils. London: Greater London Association of Community Health Councils, 1989

19 Greater London Council. Accountability and democracy in London's health service. London: GLC, 1986.

\section{Day surgery for cataracts}

\section{At least a fifth could be done this way}

In England and Wales $8 \%$ of cataract operations are done as day case surgery ${ }^{1}$; the corresponding proportion in the United States is more than 10 times this. Undoubtedly, there the impetus for day case surgery has come from insurance companies because it is cheaper, but its greater use has not been accompanied by claims of poorer surgical outcome or other disadvantages to patients. Purchasing authorities in Britain will probably demand a similar shift in health care policy.

Twenty years ago day case cataract surgery was virtually unknown in Britain, but over the past decade many places have reported favourably on its use. ${ }^{2-8}$ Its advantages include cost savings, ${ }^{45}$ a high level of satisfaction among patients, ${ }^{67}$ and complication rates that are comparable to those of inpatient surgery. ${ }^{68}$ Day case surgery is usually performed with local anaesthesia, which permits earlier ambulation and feeding and is associated with less nausea and vomiting, fewer coronary and embolic complications, and less need for postoperative nursing care-advantages reported over 30 years ago. ${ }^{9}$ Many patients unsuitable for general anaesthesia owing to conditions such as poorly controlled diabetes, chronic heart failure, or chronic asthma can have cataract surgery under local anaesthesia. Although some patients with conditions such as senile dementia or anxiety states are unsuitable for surgery under local anaesthesia, they may still be suitable for day case treatment with short acting general anaesthesia.

Postoperative follow up should follow a clear protocol that usually entails patients returning to the hospital department, although some units have found that home visits by trained nurses are practical and acceptable. ${ }^{26}$ Patients should receive clear instructions to contact the ophthalmic department if problems arise - this ensures that the workload of family doctors and community nurses does not increase. Patients lacking social support at home are probably better treated as inpatients.

Ophthalmologists may be unwilling to embark on day case surgery for several reasons. Leaver believes that the ready availability of highly trained anaesthetic staff and easy access to high quality inpatient facilities has encouraged British ophthalmologists to rely on general anaesthesia for a larger proportion of cases than do their counterparts elsewhere. ${ }^{10} \mathrm{He}$ suggests that ophthalmologists can no longer ignore opportunities for doing most types of eye surgery under local anaesthesia.

Some ophthalmologists may also be reluctant to do more surgery because this inevitably leads to more demand for postoperative follow up in already overbooked outpatient clinics. The pressure of work and inadequate facilities probably discourage many surgeons who would otherwise consider setting up day case units. Day case cataract surgery is 